\title{
Determinations of osmium isotope ratios in iron meteorites and iridosmines by ICP-MS
}

\author{
akimasa Masuda, Takafumi Hirata and Hiroshi Shimizu \\ Department of Chemistry, Faculty of Science, The University of Tokyo, Hongo, Tokyo 113, Japan
}

(Received August 15, 1986: Accepted September 10, 1986)

\begin{abstract}
Osmium isotopes in three Os reagents, four terrestiral Os-Ir alloys (iridosmine) and two iron meteorites have been measured on an inductively coupled plasma mass spectrometer (ICP-MS), with the precision of around $1 \%$ for ${ }^{187} \mathrm{Os} /{ }^{192} \mathrm{Os}$.

Comparisons are made of our isotopic ratios with the previous ones. Apart from the variation of ${ }^{187} \mathrm{Os}$ abundance as naturally expected, there seems to be a slight systematic deviation for ${ }^{189} \mathrm{Os}$. Also some discussions are given to ${ }^{184} \mathrm{Os}$.

The Os isotopic ratios for three iridosmine samples from Hokkaido, Japan, have been found quite similar to each other. The values for the Hokkaido iridosmines are $3-4 \%$ higher relative to the straight ${ }^{187}$ Os growth line obtained by Allegre and Luck (1980). Finally, the isotopic "standard" abundances (\%) for Os are presented by us: ${ }^{184} \mathrm{Os}, 0.019 ;{ }^{186} \mathrm{Os}, 1.589 ;{ }^{187} \mathrm{Os}, 1.519 ;{ }^{188} \mathrm{Os}, 13.24 ;{ }^{189} \mathrm{Os}, 16.37$; ${ }^{190} \mathrm{Os}, 26.30 ;{ }^{192} \mathrm{Os}, 40.96$. These give us the Os atomic weight $=190.24$.
\end{abstract}

\section{INTRODUCTION}

Herr et al. (1961) started Re-Os cosmochronology on the basis of the $\beta^{-}$decay of ${ }^{187} \mathrm{Re}$, but the difficulty in Os isotope measurements prevented the popular use of this method. Recent developments in a variety of mass spectrometry have allowed us easier access to Os isotope measurements. Luck et al. (1980) and Allegre and Luck (1980) established Os isotope measurements with secondary ion mass spectrometer (SIMS) and reported Re-Os age for meteorites. Since these works, geochemical and cosmochemical studies on Re-Os systematics have proceeded on the basis of Os isotope data obtained by SIMS (Luck and Allegre, 1982, 1983, 1984; Luck and Turekian, 1983; Palmer and Turekian, 1986). Luck and Allegre (1983) reported the half life value of $(4.56 \pm 0.12) \times$ $10^{10} \mathrm{y}$ based on the meteoritic isochron. On the other hand, Lindner et al. (1986) measured Os isotope ratios in $\mathrm{HReO}_{4}$ by two different types of mass spectrometers, an inductively coupled plasma mass spectrometer (ICP-MS) and a laser microprobe mass analyzer (LAMMA). They determined the ${ }^{187} \operatorname{Re}$ half-life $((4.35 \pm 0.13) \times$ $\left.10^{10} \mathrm{y}\right)$ with these measurements. The half life of ${ }^{187} \mathrm{Re}$ is similar to that of ${ }^{87} \mathrm{Rb}\left(4.88 \times 10^{10} \mathrm{y}\right)$. Further, Os isotope measurements by accelerator mass spectrometer have been reported on meteoritic and terrestrial samples (Teng et al., 1986).

$\mathrm{Re}$ and Os are siderophile or chalcophile elements. Further, it has been pointed out that $\mathrm{Re} / \mathrm{Os}$ ratio has a large fractionation factor during continental crust/mantle fractionation. These geochemical features indicate the importance of $\mathrm{Re}-\mathrm{Os}$ systematics as an isotope tracer and geo- and cosmo-chronometer. Thus, it can be said that the recent developments in mass spectrometry are strongly promoting the further progress of the Re-Os method.

In this paper, we will report Os isotope ratios in iron meteorites and iridosmines as well as Os reagents measured by ICP-MS. ICP-MS uses inductively coupled plasma (ICP) as an atmospheric ion source for a quadrupole mass spectrometer (Gray, 1975, 1985; Gray and Date, 1983; Houk et al., 1980). The most preliminary work of ours was presented at the 1985 
Annual Meeting of the Geochemical Society of Japan.

\section{Samples and Experimental Method}

Osmium tetroxide $\left(\mathrm{OsO}_{4}\right)$ reagents prepared by Strem Chemicals Inc., E. Merck Co. Inc. and Nakarai Chemicals Ltd. were used for our examination. Os isotopes in these reagents were measured for $1 \mathrm{ppm}$ Os solution $\left(1 \% \mathrm{HNO}_{3}\right.$ solution). Besides, Os isotopes were measured on two iron meteorites, Canyon Diablo and Tlacotepec. The iron meteorites were decomposed by aqua regia $\left(1: 3\right.$ mixture of $\mathrm{HNO}_{3}$ and $\left.\mathrm{HCl}\right)$ at $80-100^{\circ} \mathrm{C}$. In the decomposition process, $\mathrm{Os}$ was oxidized to volatile $\mathrm{OsO}_{4}$. The evaporated $\mathrm{OsO}_{4}$ was trapped with distilled water. The trapped $\mathrm{OsO}_{4}$ solution was free from $\mathrm{Pt}, \mathrm{W}$ and Re. Four iridosmine samples were also studied for Os isotope ratios; three samples are from Hokkaido, Japan and another is from the Urals, USSR. Iridosmine is a terrestrial Os-Ir alloy. Iridosmine samples were decomposed by sodium peroxide $\left(\mathrm{Na}_{2} \mathrm{O}_{2}\right)$ in a zirconium crucible. After decomposition, Os concentration of each sample solution was adjusted to about 1 ppm. We have confirmed that $\left(\mathrm{Zr}_{2}\right)^{+}$ions do not appear, but very weak $\mathrm{Zr}^{+}$ions are recognized in such a product. If $\left(\mathrm{Zr}_{2}\right)^{+}$appear, they affect $\mathrm{Os}^{+}$mass spectrometry.

ICP-MS used in this study was VG Isotopes PlasmaQuad. Sample solution of $1 \% \mathrm{HNO}_{3}$ was introduced to ICP-MS through the nebulizer. All of Os isotopes were measured; 184, $186,187,188,189,190$ and $192 .{ }^{192}$ Os was used as a reference isotope in this study. Os isotopic abundance obtained by Nier (1937) was used for correction of mass discrimination, which is currently inevitable as shown later. The mass discrimination as observed in ICP-MS rests mostly on the temperature of $\mathrm{RF} / \mathrm{DC}$ generator of quadrupole mass spectrometer and on the condition of electrode bias supplied to the ion lens system. Generally, for the quadrupole mass spectrometer like this, the mass discrimination effect is inevitable and is not a strictly linear function with the mass number. However, for the rather short mass range dealt with here and within the precision under consideration, one can assume the mass discrimination effect as a linear function with the mass number.

\section{Results AND Discussion}

\section{Os reagent}

Figure 1 shows two examples of Os isotopic measurement for Strem Os reagent. Ordinate in

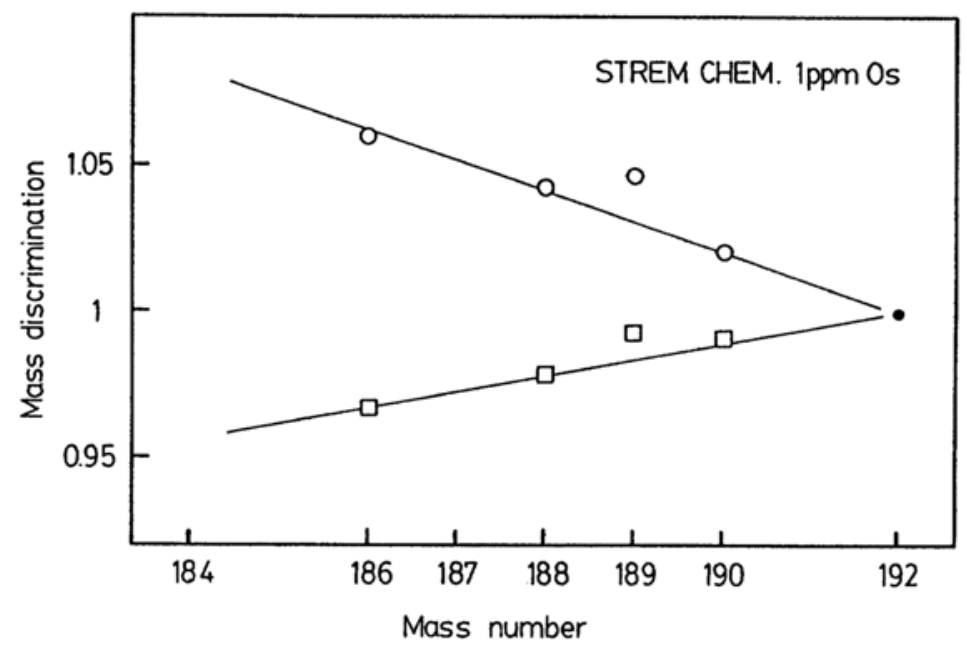

Fig. 1. Mass discrimination factor relative to Os isotope ratios of Nier (1937), employing ${ }^{192}$ Os as a "reference" nuclide. 
Fig. 1 refers to ratios of ${ }^{\mathrm{m}} \mathrm{Os} /{ }^{192} \mathrm{Os}(\mathrm{m}=184$, $186,187,188,190$ and 192) divided by the corresponding Os isotope ratios obtained by Nier (1937). Three points of ${ }^{186} \mathrm{Os} /{ }^{192} \mathrm{Os},{ }^{188} \mathrm{Os} /$ ${ }^{192} \mathrm{Os}$ and ${ }^{190} \mathrm{Os} /{ }^{192} \mathrm{Os}$ fall close to a straight line and a point of ${ }^{189} \mathrm{Os} /{ }^{192} \mathrm{Os}$ appears to deviate from this line to a certain extent. This can be understood as implying that ${ }^{180} \mathrm{Os}$ isotopic abundance obtained here differs from that by Nier.

Correction factors of mass discrimination for each isotope can be obtained from the straight line drawn by a least-squares method with respect to points of ${ }^{186} \mathrm{Os} /{ }^{192} \mathrm{Os},{ }^{188} \mathrm{Os} /$ ${ }^{192} \mathrm{Os}$ and ${ }^{190} \mathrm{Os} /{ }^{192} \mathrm{Os}$ as shown in Fig. 1. When dividing the actually observed ratios by the correction factors mathematically given by the least-square line, one can obtain the corrected ratios. Figure 2 shows ${ }^{187} \mathrm{Os} /{ }^{192} \mathrm{Os}$ and ${ }^{186} \mathrm{Os} /$ ${ }^{192} \mathrm{Os}$ ratios thus corrected, for Strem $\mathrm{OsO}_{4}$ reagent during this work. In this diagram, the precision of ${ }^{187} \mathrm{Os} /{ }^{192} \mathrm{Os}$ is about $0.4 \%\left(2 \sigma_{\mathrm{m}}\right)$. From Fig. 2, it can be seen that the precision for ${ }^{187} \mathrm{Os} /{ }^{192} \mathrm{Os}$ is much worse than that for ${ }^{186} \mathrm{Os} /{ }^{192} \mathrm{Os}$. This is due to a memory effect, because, while measuring the Strem Os reagent, we measured intermittently other two reagents having different ${ }^{187} \mathrm{Os} /{ }^{192} \mathrm{Os}$ ratios from that of Strem. If more caution is taken against such an effect, better data will be obtained. Table 1 lists Os isotopic ratios against ${ }^{192} \mathrm{Os}$ and Table 2 shows Os isotopic abundances. The Os isotopic data by Nier (1937) and Luck and Allegre (1983) are also presented in Tables 1 and 2. Figure 3 shows Os isotope data for Os reagents, corrected by mass discrimination factor as defined by the least-square line for ${ }^{186} \mathrm{Os} /{ }^{192} \mathrm{Os},{ }^{188} \mathrm{Os} /{ }^{192} \mathrm{Os}$ and ${ }^{190} \mathrm{Os} /{ }^{192} \mathrm{Os}$. As shown in Fig. 3 and Table 1, our data for ${ }^{186} \mathrm{Os} /{ }^{192} \mathrm{Os},{ }^{188} \mathrm{Os} /{ }^{192} \mathrm{Os}$ and ${ }^{190} \mathrm{Os} /{ }^{192} \mathrm{Os}$ agree well with those obtained by Nier (1937) and Luck and Allegre (1983). As for ${ }^{189} \mathrm{Os} /{ }^{192} \mathrm{Os}$ ratio, our value is close to that of Luck and Allegre, but it is $1.7 \%$ higher than that of Nier. Precision of ${ }^{184} \mathrm{Os} /{ }^{192} \mathrm{Os}$ ratio is worse than those for other Os isotope ratios, because of very low isotopic abundance of ${ }^{184}$ Os. Anyhow, ${ }^{184} \mathrm{Os} /{ }^{192} \mathrm{Os}$ ratio obtained here is close to the value by $\mathrm{Nier}$ (1937), but ${ }^{184} \mathrm{Os} /{ }^{192} \mathrm{Os}$ value obtained by Luck and Allegre (1983) is about $20-40 \%$ higher than that obtained by Nier and in this study. It is noted here that ${ }^{184} \mathrm{~W}$ is the major isotope $(30.7 \%)$ in tungsten and ${ }^{184} \mathrm{Os}$ $(0.018 \%)$ is subject to the interference by $\mathrm{W}$. The data cited in Table 1, from the work by Luck and Allegre (1983) is for their Merck standard.

Specifically, in our measurements, any $\mathrm{W}^{+}$ peaks have not been observed for Os reagents. However, when using the solutions simply prepared by dissolving the iridosmines from Nuppu River and Nizhni Tagil, we could recog-

$186_{0 s} / 1920 s=0.03881 \pm 0.00002$

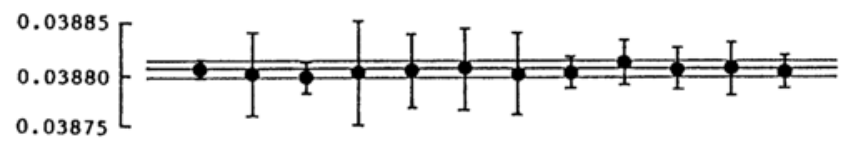

${ }^{187} 0 \mathrm{~s} / 192 \mathrm{os}=0.04862 \pm 0.00022$

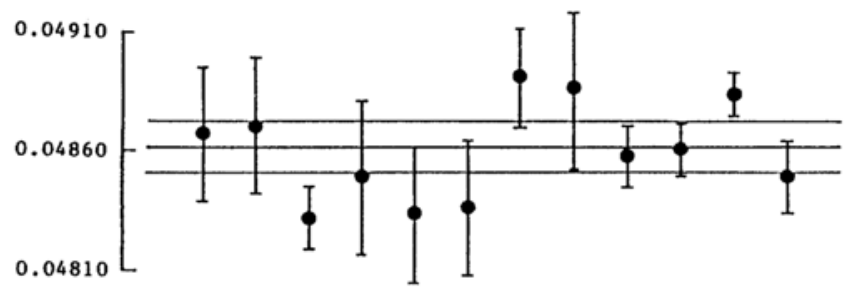

Fig. 2. ${ }^{187} \mathrm{Os} /{ }^{192} \mathrm{Os}$ and ${ }^{186} \mathrm{Os} / \mathrm{i}^{192} \mathrm{Os}$ ratios in repeated measurements of Strem Os reagent. Errors are $2 \sigma_{m}$. 
Tabble 1. Os isotope ratios against ${ }^{192}$ Os for Os reagents, together with isotopic ratios by Nier (1937) and Luck and Allegre (1983)

\begin{tabular}{lrcccrr}
\hline & \multicolumn{1}{c}{${ }^{184} \mathrm{Os}$} & \multicolumn{1}{c}{${ }^{186} \mathrm{Os}$} & ${ }^{187} \mathrm{Os}$ & ${ }^{188} \mathrm{Os}$ & ${ }^{189} \mathrm{Os}$ & \multicolumn{1}{c}{${ }^{190} \mathrm{Os}$} \\
\hline Strem & 0.00042 & 0.03881 & 0.04862 & 0.3238 & 0.4002 & 0.6428 \\
& \pm 0.00002 & \pm 0.00002 & \pm 0.00022 & \pm 0.0005 & \pm 0.0005 & \pm 0.0017 \\
Nakarai & 0.00050 & 0.0388 & 0.0463 & 0.3223 & 0.4002 & 0.6421 \\
& \pm 0.00010 & \pm 0.0014 & \pm 0.0010 & \pm 0.0016 & \pm 0.0028 & \pm 0.0020 \\
Merck & 0.00045 & 0.0387 & 0.0371 & 0.3237 & 0.3992 & 0.6416 \\
& \pm 0.00008 & \pm 0.0002 & \pm 0.0010 & \pm 0.0012 & \pm 0.0038 & \pm 0.0016 \\
Average* & 0.00046 & 0.0388 & - & 0.3233 & 0.3998 & 0.6422 \\
$\quad$ (I) & \pm 0.00004 & \pm 0.0001 & - & \pm 0.0009 & \pm 0.0006 & \pm 0.0007 \\
Average** & 0.00042 & 0.0388 & - & 0.3237 & 0.4000 & 0.6421 \\
$\quad$ (II) & \pm 0.00002 & \pm 0.0001 & - & \pm 0.0006 & \pm 0.0002 & \pm 0.0007 \\
Nier & 0.00049 & 0.0388 & 0.0393 & 0.3244 & 0.3927 & 0.6439 \\
Luck \& & 0.00059 & 0.03904 & 0.03687 & $0.32439 * * *$ & 0.39679 & 0.64382 \\
Allegre & \pm 0.00006 & \pm 0.00002 & \pm 0.00002 & & \pm 0.00011 & \pm 0.00026 \\
\hline
\end{tabular}

Errors are $2 \sigma_{m}$.

* Average (I): arithmetical mean.

** Average (II): weighted mean, taking into account the statistical fluctuations in measurement.

${ }^{* * *}$ Luck and Allegre (1983) used ${ }^{192} \mathrm{Os} /{ }^{188} \mathrm{Os}=3.08271$ for normalization.

nize the $\mathrm{W}^{+}$peaks. Their peak heights were such as to affect to some extent only ${ }^{184} \mathrm{Os}$. In the case a reliable value for ${ }^{184}$ Os relative abundance is needed for iridosmine, we are currently employing the separation of Os vapor from the simply dissolved sample solution. For meteorites, we also carried out the Os vapor separation.

It might merit notice that ${ }^{190} \mathrm{Pt}$ decays into ${ }^{186} \mathrm{Os}$ with the half-life of $5.9 \times 10^{11} \mathrm{y}$. The isotopic abundances of ${ }^{190} \mathrm{Pt}(0.0127 \%)$ and ${ }^{186} \mathrm{Os}(1.59 \%)$ and the decay constant concerned suggest that the possible isotopic variation of the latter nuclide should be far smaller than the current detection limits but can be detected in unusually Pt-rich minerals. Hence some uneasiness may remain in discussing ${ }^{187} \mathrm{Os}$ relative to ${ }^{186} \mathrm{Os}$. At present, however, discussions about ${ }^{187} \mathrm{Os}$ will be given in terms of ${ }^{187} \mathrm{Os} /$ ${ }^{186} \mathrm{Os}$, following the way currently adopted.

Isobaric effect on ${ }^{186} \mathrm{Os}(1.59 \%)$ by ${ }^{186} \mathrm{~W}$ $(28.4 \%)$ could not be so serious as the similar one on ${ }^{184} \mathrm{Os}$ by ${ }^{184} \mathrm{~W}$ so long as the ordinary caution is taken in separation of Os from W. The W-Os interference can be detected by sweeping the mass range involving tungsten isotopes. But the effect as noted here might become an additional reason to let us prefer ${ }^{187} \mathrm{Os} /{ }^{188} \mathrm{Os}$ ratio to ${ }^{187} \mathrm{Os} /{ }^{186} \mathrm{Os}$ in geochemical discussions.

Table 2. Osmium isotopic abundances (\%)

\begin{tabular}{llllllll}
\hline & ${ }^{184} \mathrm{Os}$ & ${ }^{186} \mathrm{Os}$ & ${ }^{187} \mathrm{Os}$ & ${ }^{188} \mathrm{Os}$ & ${ }^{189} \mathrm{Os}$ & ${ }^{190} \mathrm{Os}$ & ${ }^{192} \mathrm{Os}$ \\
\hline This study* & & & & & & & \\
$\quad$ A & 0.019 & 1.582 & 1.982 & 13.18 & 16.30 & 26.18 & 40.76 \\
B & 0.019 & 1.589 & 1.519 & 13.24 & 16.37 & 26.30 & 40.96 \\
Nier** & 0.018 & 1.59 & 1.64 & 13.2 & 16.1 & 26.4 & 41.0 \\
Luck \& Allegre*** & 0.024 & 1.599 & 1.510 & 13.29 & 16.25 & 26.37 & 40.96 \\
\hline
\end{tabular}

* These isotopic abundances were calculated from the arithmetical mean of the Os ratios in Table 1 , except for ${ }^{187} \mathrm{Os} /{ }^{192} \mathrm{Os}$; “ $A$ " was based on the ${ }^{187} \mathrm{Os} /{ }^{192} \mathrm{Os}$ ratio for Strem Os reagent and " $B$ " on the ${ }^{187} \mathrm{Os} /{ }^{192}$ Os ratio for Merck Os reagent.

** Nier (1937).

*** Luck and Allegre (1983) for Merck Os reagent. 


\section{Iron meteorites and iridosmines}

Os isotopic ratios for iron meteorites and iridosmines are shown in Table $3 .{ }^{187} \mathrm{Os} /{ }^{186} \mathrm{Os}$ ratios are 1.066 and 1.033 for Canyon Diablo and Tlacotepec, respectively. Luck and Allegre (1983) reported ${ }^{187} \mathrm{Os} /{ }^{186} \mathrm{Os}$ ratios of 1.115 and 1.113 for Canyon Diablo and of $0.980,0.994$ and 1.008 for Tlacotepec. We cannot rule out a possibility that the numerical differences between those by Luck and Allegre and ours may be due to the heterogeneity in $\mathrm{Re} / \mathrm{Os}$ ratios in the iron meteorite specimens.

Three iridosmine samples from Hokkaido (Kodaira, Nuppu River and Usotannai) are considered to be associated with ultra-mafic rocks in the Kamuikotan metamorphic belt. Metamorphic age for the Kamuikotan belt is thought to be about $100 \mathrm{~m}$.y. Iridosmine from the Urals (Nizhni Tagil) is associated with ultramafic rocks (300-400m.y.) in the "Hercynian ophiolite belt". Allegre and Luck (1980)

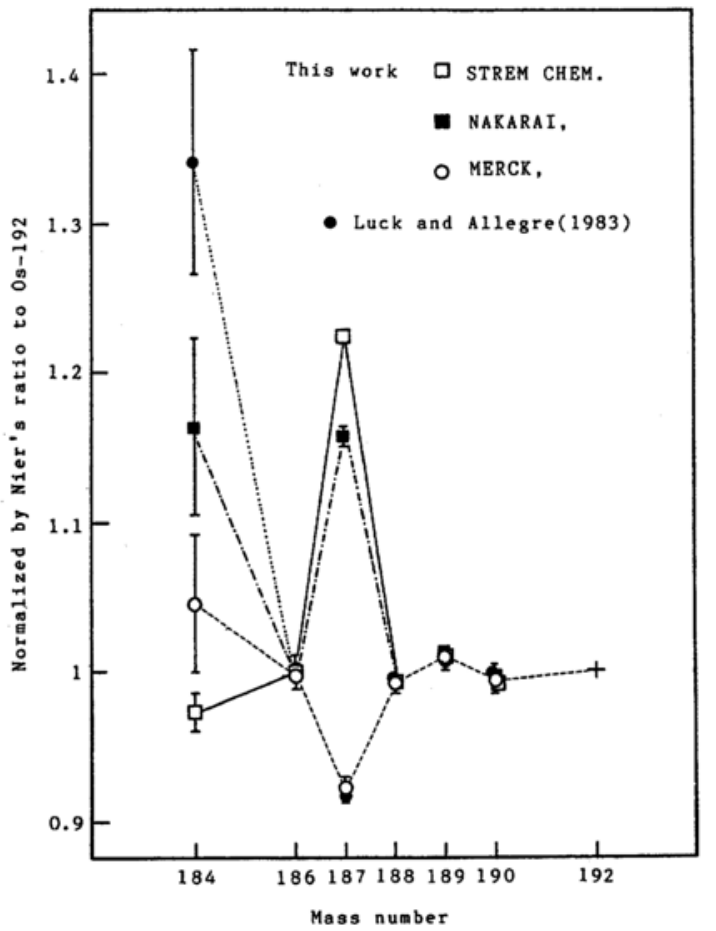

Fig. 3. Relative Os isotope ratios to ${ }^{192} \mathrm{Os}$ for $\mathrm{Os}$ reagents, together with Os isotope ratios obtained by Luck and Allegre (1983). Errors are $2 \sigma_{m}$. (For corrections for mass discrimination, see text.)
Table 3. Osmium isotopic ratio for iron meteorites and iridosmines

\begin{tabular}{lrrr}
\hline & \multicolumn{1}{c}{${ }^{186} \mathrm{Os} /{ }^{192} \mathrm{Os}$} & ${ }^{187} \mathrm{Os} /{ }^{192} \mathrm{Os}$ & ${ }^{187} \mathrm{Os} /{ }^{186} \mathrm{Os}$ \\
\hline Iron Meteorite* & & & \\
Canyon Diablo & 0.0391 & 0.0417 & 1.066 \\
& \pm 0.0012 & \pm 0.0008 & \pm 0.038 \\
Tlacotepec & 0.0389 & 0.0402 & 1.033 \\
& \pm 0.0006 & \pm 0.0008 & \pm 0.020 \\
& & & \\
Iridosmine* & & & \\
Kodaira, Hokkaido & 0.0387 & 0.0415 & 1.072 \\
& \pm 0.0002 & \pm 0.0006 & \pm 0.016 \\
Nuppu River, Hokkaido & 0.0388 & 0.0414 & 1.067 \\
& \pm 0.0010 & \pm 0.0006 & \pm 0.032 \\
Usotannai, Hokkaido & 0.0387 & 0.0412 & 1.065 \\
& \pm 0.0004 & \pm 0.0004 & \pm 0.016 \\
Nizhni Tagil, The Urals & 0.0388 & 0.0393 & 1.013 \\
& \pm 0.0002 & \pm 0.0005 & \pm 0.006 \\
\hline
\end{tabular}

Errors are $2 \sigma_{m}$.

* Amounts of samples used are ca. $1 \mathrm{~g}$ for iron meteorite and ca. $1 \mathrm{mg}$ for iridosmine.

reported ${ }^{187} \mathrm{Os} /{ }^{186} \mathrm{Os}$ ratio for "osmiridium" samples of various ages from 90 to 2,700 m.y. Their conclusion is that the ${ }^{187} \mathrm{Os} /{ }^{186} \mathrm{Os}$ variation with time can be fitted by a straight line corresponding to ${ }^{187} \mathrm{Re} /{ }^{186} \mathrm{Os}=3.15$ for the mantle, comparable to $\mathrm{Cl}$ carbonaceous chondrites.

Our ${ }^{187} \mathrm{Os} /{ }^{186} \mathrm{Os}$ ratio $(1.013)$ for the sample from the Urals is somewhat lower than that $(1.036 \pm 0.004)$ reported by Allegre and Luck (1980). Our value appears to fall on the straight line mentioned above, while their value deviates somewhat from it.

As seen in Table 3 , the ${ }^{187} \mathrm{Os} /{ }^{186} \mathrm{Os}$ ratios (1.065-1.072) for three Hokkaido iridosmines are quite similar to each other. Assuming the fixation of ${ }^{187} \mathrm{Os} /{ }^{186} \mathrm{Os}$ ratio $100 \mathrm{~m}$.y. ago corresponding to the metamorphic age, we consider that the Hokkaido iridosmine ratio is $3-4 \%$ higher as compared with the Allegre-Luck's straight line. If the fixation age is older than the metamorphic age, the difference from the straight line would tend to increase. This difference could be explained either as reflecting some possible variation of ${ }^{187} \mathrm{Os} /{ }^{186} \mathrm{Os}$ ratio in the mantle source, or as due to a small extent of contamination by the crustal source. The explanation in terms of the latter effect might be unfavorable in view of the considerably high homogeneity for three samples studied 
here, but it would be premature to give conclusive words to this matter yet. One cannot rule out a third possibility such as doublestage evolution of the mantle and even a fourth one related with the systematic aberration in measurements. But, in view of the variation in meteoritic ${ }^{187} \mathrm{Os} /{ }^{186} \mathrm{Os}$ ratios as observed by Luck and Allegre (1983) and in the present study for Canyon Diablo and Tlacotepec, it is most likely that the deviation observed here is due to some heterogeneity of Re-Os ratio in the mantle source.

Meanwhile, Morgan (1985) discussed the $\mathrm{Os} / \mathrm{Re}$ ratios for the mantle source, in relation with the $\mathrm{Os} / \mathrm{Re}$ ratios in classified chondrite groupings. He maintains that the appropriate $\mathrm{Os} / \mathrm{Re}$ value for the earth's mantle source should be 12.06 by weight, corresponding to ${ }^{187} \mathrm{Re} /{ }^{186} \mathrm{Os}=3.32$. If similar calculation is made for the Hokkaido iridosmine, we can get ${ }^{187} \mathrm{Re} /{ }^{186} \mathrm{Os}=3.27$, which falls between 3.15 (Allegre and Luck, 1980) and 3.32 (Morgan, 1985).

In summary, isotope ratios of osmium for osmium tetroxide reagents, iridosmines and iron meteorites have been measured by ICP-MS, with the relative precision of around $1 \%$ for ${ }^{187} \mathrm{Os} /{ }^{192} \mathrm{Os}$ ratio. Some minor differences have been observed in Os isotopic abundances among the data by Nier (1937), Luck and Allegre (1983) and this study; slightly lower abundance of ${ }^{189} \mathrm{Os}$ in the data of Nier and higher abundance of ${ }^{184} \mathrm{Os}$ in the data of Luck and Allegre. We think that the isotopic abundances indicated by $\mathrm{B}$ in Table 2 are recommendable as standard values. Based on this data, one can obtain the atomic weight for Os to be 190.24.

Acknowledgements-We would like to express our gratitude to Dr. A. Kato, National Museum of Natural History, Japan, for his helpful information. Iridosmine from Nizhni Tagil, the Urals, USSR, was offered by Dr. P. T. Dunn, National Museum of Natural History, Smithsonian Institution, Washington D. C. The kind arrangements in offering the Tlacotepec meteorite specimens from Dr. E. J. Olsen, Field Museum of Natural History and Dr. C. O'Neil, American Museum of Natural History, are gratefully acknowledged. This work was supported by granti-in-aid for Scientific Research from the Ministry of Education, Science and Culture of Japan.

\section{REFERENCES}

Allegre, C. J. and Luck, J.-M. (1980) Osmium isotopes as petrogenetic and geological tracers. Earth Planet. Sci. Lett. 48, 148-154.

Gray, A. L. (1975) Mass-spectrometric analysis of solutions using an atmospheric pressure ion source. Analyst 100, 289-299.

Gray, A. L. (1985) The ICP as an ion source - origins, achievements and prospects. Spectrochimica Acta 40B, 1525-1537.

Gray, A. L. and Date, A. R. (1983) Inductively coupled plasma source mass spectrometry using continuum flow ion extraction. Analyst 108, 10331050.

Herr, W., Hoffmeister, W., Hirt, B., Geiss, J. and Houtermans, F. G. (1961) Versuch zur Datiering von Eisen Meteoriten nach der Rhenium-Osmium Methode. Z. Naturforsch. 16, 1053-1056.

Houk, R. S., Fassel, V. A., Flesch, G. D., Svec, H. J., Gray, A. L. and Taylor C. E. (1980) Inductively coupled argon plasma as an ion source for mass spectrometric determination of trace elements. Anal. Chem. 52, 2283-2289.

Lindner, M., Leich, D. A., Borg, R. J., Russ, G. P., Bazen, J. M., Simons, D. S. and Date, A. R. (1986) Directly laboratory determination of the ${ }^{187} \mathrm{Re}$ halflife. Nature 320, 246-248.

Luck, J.-M. and Allegre, C. J. (1982) The study of molybdenites through the ${ }^{187} \mathrm{Re}^{187} \mathrm{Os}$ chronometer. Earth Planet. Sci. Lett. 61, 291-296.

Luck, J.-M. and Allegre, C. J. (1983) ${ }^{187} \mathrm{Re}^{187} \mathrm{Os}$ systematics in meteorites and cosmochemical consequences. Nature 302, 130-132.

Luck, J.-M. and Allegre, C. J. (1984) ${ }^{187} \mathrm{Re}^{187} \mathrm{Os}$ investigation in sulfide from Cape Smith komatiite. Earth Planet. Sci. Lett. 68, 205-208.

Luck, J.-M. and Turekian, K. K. (1983) Osmium-187/ osmium-186 in manganese nodules and the Cretaceous-Tertiary boundary. Science 222,613-615.

Luck, J.-M., Brick, J.-L. and Allegre, C. J. (1980) ${ }^{187} \mathrm{Re}^{187} \mathrm{Os}$ systematics in meteorites: early chronology of the solar system and age of the Galaxy. Nature 283, 256-259.

Morgan, J. W. (1985) Osmium isotope constraints on Earth's late accretionary history. Nature 317, 703705.

Nier, A. O. (1937) The isotopic constitution of osmium. Physical Review 52, 885.

Palmer, M. R. and Turekian, K. K. (1986) ${ }^{187} \mathrm{Os} /$ 
${ }^{186} \mathrm{Os}$ in marine manganese nodules and the constraints on the crustal geochemistries of rhenium and osmium. Nature 319, 216-220.

Teng, R., Fehn, U., Elmore, D., Kubik, P. W. and Gove,
H. E. (1986) Osmium isotope ratios determined in low level samples using accelerator mass spectrometry and a nickel sulphide preconcentration method (Abstract). Terra cognita 6, 122. 